\title{
Safety, Tolerability and Pharmacokinetics of Vidofludimus calcium (IMU-838) After Single and Multiple Ascending Oral Doses in Healthy Male Subjects
}

\author{
Andreas Muehler ${ }^{1} \cdot$ Hella Kohlhof ${ }^{1} \cdot$ Manfred Groeppel $^{1} \cdot$ Daniel Vitt $^{1}$
}

Published online: 2 May 2020

(c) The Author(s) 2020

\begin{abstract}
Background and Objective Vidofludimus is a potent and selective inhibitor of human mitochondrial enzyme dihydroorotate dehydrogenase (DHODH). The clinical efficacy and safety profile of vidofludimus has been analyzed in patients suffering from rheumatoid arthritis and Crohn's disease and ulcerative colitis. In previous sudies, hematuria at higher doses occurred in close temporal relationship to vidofludimus administration and appeared to be dose related. The present report describes the results from two phase 1 studies conducted in healthy male subjects to investigate the safety, tolerability and pharmacokinetics after single and multiple ascending (SAD and MAD) oral doses of IMU-838 (vidofludimus calcium, tablets containing a specific polymorph). The effect of food on the pharmacokinetics of IMU-838 was also assessed in the SAD study.

Methods In the SAD study, 12 subjects received single doses of IMU-838 under fasting (10-40 mg) or fed (10 mg) condition in an open-label, partial parallel group design. In the MAD study, 52 subjects received multiple doses of IMU-838 (30-50 mg) in a double-blind, placebo-controlled, parallel group design.

Results IMU-838 showed dose-proportional pharmacokinetics after single and multiple oral dosing in both SAD and MAD studies. IMU-838 was well absorbed after single daily doses. Food did not impact the pharmacokinetics of IMU-838. The accumulation factor for multiple daily dosing was approximately 2 . Steady-state concentrations were reached within about 6-8 days for 30-50 mg groups. The geometric mean plasma half-life of IMU-838 at steady state was approximately $30 \mathrm{~h}$, which supports its use for once-daily dosing regimen. Single and multiple oral doses of IMU-838 were safe and well tolerated. Conclusion Overall, oral IMU-838 was generally well tolerated in SAD and MAD studies in healthy subjects over a wide dose range of 10-50 mg. IMU-838 was well absorbed after single daily doses. IMU-838 showed dose proportional pharmacokinetics after single and multiple oral dosing.
\end{abstract}

\section{Introduction}

Vidofludimus, the active moiety and free acid form of IMU-838, is a potent and selective inhibitor of human mitochondrial enzyme dihydroorotate dehydrogenase (DHODH), which is only expressed at high levels and relevant in metabolically activated lymphocytes [1-3]. The activity of DHODH is the rate-limiting step in pyrimidine synthesis to support the enhanced nucleotide demand for

Electronic supplementary material The online version of this article (https://doi.org/10.1007/s13318-020-00623-7) contains supplementary material, which is available to authorized users.

Andreas Muehler

andreas.muehler@imux.com

1 Immunic AG, Am Klopferspitz 19, 82152 Planegg-Martinsried, Germany messenger ribonucleic acid (mRNA) and deoxyribonucleic acid (DNA) synthesis in highly activated lymphocytes [4, 5]. The inhibition of DHODH in these cells leads to induction of a metabolic stress signal initiating an immediate block of transcription of pre-loaded genes like certain cytokines. If the metabolic stress signal holds on because of prolonged DHODH inhibition, pro-apoptotic transcripts are stabilized, and apoptosis is induced $[3,6]$. Normal-acting lymphocytes without a high metabolic turnover do not depend on de novo pyrimidine synthesis but can satisfy their pyrimidine requirements through the DHODH-independent salvage pathway $[3,7]$. Therefore, inhibition of DHODH by vidofludimus selectively affects highly activated lymphocytes like phytohemagglutinin (PHA) stimulated lymphocytes in vitro or highly activated and chronically stimulated lymphocytes in autoimmune and chronic inflammatory diseases. Klotz et al. have demonstrated that those lymphocytes with the highest affinity to the antigen and the highest metabolic 


\section{Key Points}

This article reports the safety, tolerability and pharmacokinetics after single and multiple ascending (SAD and MAD) oral doses of IMU-838 (vidofludimus calcium) from two phase 1 studies conducted in healthy male subjects

This is significant because oral IMU-838 offers favorable pharmacokinetic characteristics and is well tolerated in SAD and MAD studies in healthy subjects over a wide dose range of $10-50 \mathrm{mg}$

IMU-838 showed dose-proportional pharmacokinetics after single and multiple oral dosing

A preliminary population pharmacokinetic model has been developed to support the further analysis of sparse pharmacokinetic data planned to be collected in the future phase 2 studies

activity are the most sensitive cells to DHODH inhibition [8]. Furthermore, vidofludimus is a very potent inhibitor of interleukin (IL)-17 and interferon-gamma (IFN- $\gamma$ ) release from stimulated immune cells. The efficacy of vidofludimus has been demonstrated in several animal disease models for inflammatory bowel disease (IBD) [2] as well as systemic lupus erythematosus (SLE) [1], multiple sclerosis (experimental autoimmune encephalitis, EAE) [9] and transplant rejection [10]. In hepatocytes, a total of eight metabolites are identified across different species, six of the eight metabolites in human hepatocytes. The main metabolite in humans was formed via $O$-demethylation. A study using human liver microsomes with and without cytochrome P450 (CYP)selective inhibitors, and using human recombinant enzymes, showed that cytochrome CYP2C8 was the predominant hepatic CYP isoform involved in metabolism of vidofludimus, with smaller contributions by CYP2C9 (data on file).

Vidofludimus in its form as free acid (lab code: SC12267) using capsules or tablets containing amorphous vidofludimus (previous formulation name: 4SC-101) previously underwent a phase 1 and 2 clinical development program. The clinical efficacy and safety profile of vidofludimus (free acid) were analyzed in clinical studies in healthy volunteers [4] and patients suffering from rheumatoid arthritis $[11,12]$ and Crohn's disease and ulcerative colitis [4]. Single doses up to $350 \mathrm{mg}$ and multiple doses up to $70 \mathrm{mg}$ for 14 days have been tested in healthy volunteers. Patients with rheumatoid arthritis, Crohn's disease and ulcerative colitis have been exposed to daily doses of 20 or $35 \mathrm{mg}$ vidofludimus with individual treatment durations of 12-13 weeks [4, 11, 12]. An in-depth analysis of the whole clinical database has demonstrated that vidofludimus free acid at daily doses $<70 \mathrm{mg}$ is not associated with an increased rate of clinically relevant adverse reactions. High doses of vidofludimus administered in the single- and multiple-dose phase 1 studies showed presumably drug-associated events of hematuria. Cases of hematuria occurred exclusively at single doses of $210 \mathrm{mg}$ vidofludimus (free acid) or higher and at daily doses of $70 \mathrm{mg}$ vidofludimus (free acid). These occurred in close temporal relationship to study drug administration and appeared to be dose related. Although there is no strict dose correlation, very high doses of vidofludimus in the phase 1 trials seemed to also result in lowering of serum uric acid levels. Urinary crystallization of uric acid in acidic urine may be speculated to be the event mechanism for these events of hematuria at multiple doses of $70 \mathrm{mg}$ or higher [12]. For this reason, the doses in this trial were selected to not exceed the AUC found in the previous phase 1 trial (SC12267-2-2004) of $70 \mathrm{mg}$ daily repeated $\mathrm{SC} 12267\left(\mathrm{AUC}_{0-24, \mathrm{ss}}\right.$ of $\left.259.5 \mathrm{~h} \mathrm{\mu g} / \mathrm{ml}\right)$, which led to the findings of hematuria (data on file).

Immunic AG has developed a new pharmaceutical form containing the calcium salt of vidofludimus (lab code: IM90838; INNM: vidofludimus calcium) in a new pharmaceutical formulation (tablets containing a specific polymorph) with the designated formulation name of IMU-838. IMU-838 is under development as an oral tablet formulation for the treatment of relapsing-remitting multiple sclerosis (RRMS), IBD and other chronic inflammatory and autoimmune diseases. This report describes the results from two phase 1 studies conducted in healthy male subjects to investigate the safety, tolerability and pharmacokinetics after single and multiple ascending (SAD and MAD) oral doses of IMU-838. In the single-dose study, food effect on the pharmacokinetics of IMU-838 was also assessed.

\section{Methods}

\subsection{Ethics Approval}

The protocols for SAD and MAD studies were approved by the Institutional Ethics Committee (IEC). The studies were conducted in compliance with ethical standards for human experimentation established by the Declaration of Helsinki principles, the International Conference on Harmonization (ICH) and the Guideline of Good Clinical Practice (GCP). Both SAD and MAD studies were conducted at a single center, Nuvisan GmbH, Germany.

\subsection{Study Participants}

Twelve (in the SAD study) and 52 (in the MAD study) healthy male subjects between 18 and 55 years of age inclusive, body mass index (BMI) between 18 and $30 \mathrm{~kg} / \mathrm{m}^{2}$ 
inclusive and smoking $\leq 5$ cigarettes/day were included in the studies. As the monitoring of erythrocytes in urine was a major safety objective in this trial, no female subjects were included because menses is known to cause artificial hematuria. No difference is expected between male and female subjects as no preclinical studies had observed any differences between different genders. The summary of demographic data for SAD and MAD studies is given in Table 1. Informed consent was obtained from all subjects before participation in the studies. The complete details of inclusion and exclusion criteria are presented in Supplementary Appendix 1 (SAD and MAD study). Only the subjects who complied with all selection criteria were enrolled into the trial. IMU-838 tablets were used in the strengths of 10, 15 and $20 \mathrm{mg}$. In both SAD and MAD studies, blood samples were collected and centrifuged within $45 \mathrm{~min}$ of blood draw. A vial (3.0 ml K2 EDTA-Vacutainer) was centrifuged for $10 \mathrm{~min}$ at $\sim 2000 \mathrm{~g}$ in a precooled centrifuge $\left(5^{\circ} \mathrm{C}\right)$. After centrifugation, a pipette was used to extract two samples of $0.3 \mathrm{ml}$ plasma (main and backup sample). These plasma samples were stored at $-20{ }^{\circ} \mathrm{C}$ up to measurements. The storage condition was validated for up to 3 months.

\subsection{Study Design}

\subsubsection{Study 1: SAD Study}

Study 1 had an open-label, partial parallel group design, with escalating single oral doses of IMU-838 in 12 healthy male subjects. The primary objective of the study was to assess the pharmacokinetics of IMU-838 while the secondary objective was to assess the safety and tolerability of IMU-838 and to assess the effect of food intake on bioavailability of IMU-838 in healthy male subjects. Healthy male subjects were divided in two groups. In group 1, subjects $(n=6)$ received two single ascending doses in the fasted state (10 and $30 \mathrm{mg}$ ) and a single dose of $10 \mathrm{mg}$ IMU-838 after a standardized breakfast in a third period. In group 2, subjects $(n=6)$ received two single doses in the fasted state (20 and $40 \mathrm{mg}$ ).

Drug administration took place in the morning with appropriate intervals between subjects to allow for sample collection and any necessary additional clinical observations. Blood samples were collected and plasma was analyzed for IMU-838 concentrations at pre-dose and at 0.5 , $1,2,3,4,5,6,8,10,12,16,24,36,48,60,72,96,120$ and $168 \mathrm{~h}$ after dosing. There was a washout of at least 14 days between administrations in the same subject. Fasted drug administration was performed after an overnight fast of $10 \mathrm{~h}$, which was continued for a further $4 \mathrm{~h}$. Fed administration was performed $30 \mathrm{~min}$ after start of a standardized breakfast. Urine samples were collected for $24 \mathrm{~h}$ prior to dosing, and

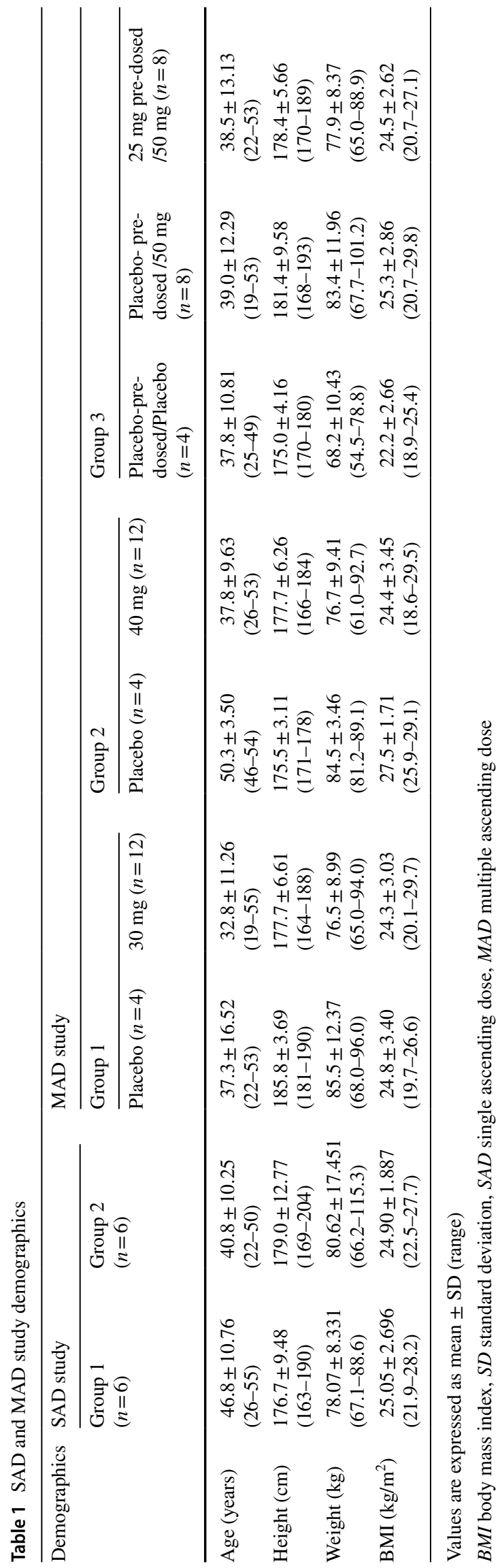


a sample of the post-dose $24 \mathrm{~h}$ urine collection was used for determination of the amount of drug excreted.

Subjects were hospitalized from day -1 until discharge on the morning of day 3 ( $72 \mathrm{~h}$ after dosing). After completion of all 48-h assessments of a dosing period, safety and drug concentration data were reviewed, and the next dose increment was decided on by the sponsor and the investigator. There was a time interval of at least 1 week between two consecutive dosing groups (periods) to allow a careful analysis of the safety parameters of the previous dose group. The decision to proceed with the next higher scheduled dose was taken upon mutual agreement between the sponsor and the investigator and required availability of relevant pharmacokinetic and safety data of the previous dose group. One subject withdrew for personal reasons after completion of period 1 assessments. All other subjects completed the study as planned. All subjects were included in the safety and pharmacokinetic set.

\subsubsection{Study 2: MAD Study}

Study 2 was a double-blind, placebo-controlled, parallel group design with escalating multiple doses of IMU-838 using an adaptive dose-finding design (for dose escalation and de-escalation) in 52 healthy male subjects. The primary objective of the study was to assess the multiple-dose pharmacokinetics of IMU-838 while the secondary objective was to assess the safety and tolerability of multiple doses of IMU-838 in healthy male subjects.

Three consecutive groups of healthy male subjects were used; an optional fourth group was not dosed. The first group of 16 subjects (12 subjects on IMU-838 and 4 on placebo) received $30 \mathrm{mg}$ IMU-838 or placebo once daily over 14 consecutive days. Following the $30 \mathrm{mg}$ starting dose (dose group 1), further dose groups had either of two alternative group designs:

Alternative design A: 14-day once daily dosing (12 subjects received IMU-838 and 4 subjects received placebo), Alternative design B: 14-day once daily dosing (16 subjects received IMU-838 and 4 subjects received placebo). Preceding the 14-day dosing period, an initiation dose period where subjects received one daily dose during 6 days (day -6 to -1 ) was initiated:

- Eight of 16 subjects randomized to IMU-838 received half of the dose planned for days 0 to 13 ,

- Eight of 16 subjects randomized to IMU-838 received placebo doses,

- Four subjects randomized to placebo received placebo doses.
After completion of all day 14 assessments of each dose group, safety and drug concentration data were analyzed and a decision was made about whether:

- the study was to be discontinued,

- the dose was to be escalated and to which new dose level, or

- the dose was to be lowered to an intermediary dose.

If no stopping rules were reached, and the safety and pharmacokinetic data were deemed to be acceptable, the next dose group was to be started with a dose that could be up to 1.5-fold higher than the previous dose group. The decision to proceed with the next higher scheduled dose was taken upon mutual agreement between the sponsor and the investigator. There was a time interval of at least 1 week between the end of dosing in one group and start of the next dosing group to allow a careful analysis of the safety and plasma concentrations of IMU-838 of the previous dose group.

After the first dose group (30 mg IMU-838 and placebo), two additional dose groups were performed: one-dose group (40 mg IMU-838 or placebo) with alternative group design A and one-dose group (50 mg IMU-838 or placebo) with alternative group design $\mathrm{B}$.

Drug administration was performed after an overnight fast of at least $8 \mathrm{~h}$, which was continued for further $1 \mathrm{~h}$ on the pharmacokinetic profile days. On all other days, dosing was performed in the morning in the fasted state approximately $15 \mathrm{~min}$ to $1 \mathrm{~h}$ before breakfast. Blood samples were collected and plasma was analyzed for IMU-838 concentrations at different time intervals: pre-dose (within 120 min prior to drug administration) and 0.5, 1, 2, 3, 4, 5, 6, 8, 10, 12, 16 and $24 \mathrm{~h}$ after the first dose on day 0 (13 samples); trough concentrations on days 2, 4, 6, 8, 10, 11 and 12 (7 samples); pre-dose (within 15 min prior to drug administration) and $0.5,1,2,3,4,5,6,8,10,12,16,24,36,48$ and $72 \mathrm{~h}$ after the last dose on day 13 (16 samples); and a final sample $240 \mathrm{~h}$ after the last dosing (day 23). Urine samples were collected for $24 \mathrm{~h}$ prior to dosing, and a sample of the post-dose $24 \mathrm{~h}$ urine collection was used for determination of the amount of drug excreted. The MAD study design is presented in Table 2. If no stopping rules were reached, and the safety and pharmacokinetic data were deemed acceptable, the next dose group was to be started with a dose that could be up to 1.5-fold higher than the in previous dose group (i.e., the second group may receive between 35 and $45 \mathrm{mg}$, depending on the data in the starting dose group). The selected dose steps were $40 \mathrm{mg}$ for the second dose group and $50 \mathrm{mg}$ IMU-838 for the third dose group. There was a time interval of at least 1 week between the end of dosing in one group and start of the next dosing group to allow a careful analysis of the safety and plasma concentrations of IMU-838 of the 
previous dose group. For any dose group without an initiation dose period (alternative A), subjects were hospitalized from day -1 until day 4 ( $100 \mathrm{~h}$ after dosing) and again from day 12 until day 14 ( $24 \mathrm{~h}$ after the last drug administration). For any dose group that included an initiation dose period (alternative B), subjects were additionally hospitalized from day -7 until day -5 .

\subsection{Endpoints and Assessments}

\subsubsection{Bioanalysis}

All samples were stored at $-20{ }^{\circ} \mathrm{C}$ until they were analyzed. Plasma and urine IMU-838 concentrations were analyzed using a validated liquid chromatography with a tandem mass spectrometry (LC-MS/MS) method. The LC-MS/ MS system consists of an Applied Biosystems API 4000 mass spectrometer, chromatographic system of an Agilent 1200 series G1312A/B binary pump, Agilent 1200 series G1322/A degasser and Agilent 1200 series G1316A column oven, and an HTC PAL autosampler CTC analytics. The assay method involved a protein precipitation of samples with the internal standard (SC-13093), a chromatographic separation on a Luna $\mathrm{C}_{8}(50 \times 2.0 \mathrm{~mm}, 3 \mu \mathrm{m})$ column and LC-MS/MS detection. The lower limit of quantitation for the assay was $0.100 \mu \mathrm{g} / \mathrm{ml}$, and the linear calibration range was $0.100-25.0 \mu \mathrm{g} / \mathrm{ml}$. The mobile phase used was: mobile phase A $[0.7708 \mathrm{~g}$ ammonium acetate $+1000 \mathrm{ml}$ high-performance liquid chromatography (HPLC)-water adjust to $\mathrm{pH}$ 5 with acetic acid] and mobile phase B (acetonitrile). The purge solution was: purge solution 1 (500 $\mu \mathrm{l}$ formic acid and $500 \mathrm{ml}$ HPLC-water) and purge solution 2 (200 ml HPLCwater, $300 \mathrm{ml}$ acetonitrile and $1.00 \mathrm{ml}$ ammonia solution). The electrospray (atmospheric pressure ionization) technique was used in negative ion $\left(\mathrm{ESI}^{-}\right)$mode. The injection volume was $20.0 \mu \mathrm{l}$ (in the SAD study) and 5.0-10.0 $\mu \mathrm{l}$ (in the MAD study), and the flow rate was $0.300 \mathrm{ml} / \mathrm{min}$.

\subsubsection{Pharmacokinetics}

For single- and multiple-dose pharmacokinetics, the area under the concentration-time curve (AUC) was calculated during the interval from $0 \mathrm{~h}$ to the last timepoint with a quantifiable concentration $\left(\mathrm{AUC}_{0-\mathrm{t}}\right)$ or during $24 \mathrm{~h}\left(\mathrm{AUC}_{0-24}\right)$ by the linear-log trapezoidal method. The AUC from $0 \mathrm{~h}$ to infinity $\left(\mathrm{AUC}_{0-\infty}\right)$ was calculated by adding the last sample with a quantifiable concentration $\left(C_{\mathrm{z}}\right) /$ terminal elimination rate constant $\left(\lambda_{\mathrm{z}}\right)$ to $\mathrm{AUC}_{0-\mathrm{t}}$. $\% \mathrm{AUC}_{\text {extrap }}$ was the ratio of the extrapolated part within $\mathrm{AUC}_{0-\infty}$ in percentage. The apparent terminal rate constant $\left(\lambda_{\mathrm{z}}\right)$ was calculated by log linear regression on the terminal phase. The half-life $\left(t_{1 / 2}\right)$ was calculated as $(\ln 2) / \lambda_{\mathrm{z}}$. The apparent total clearance $(\mathrm{CL} / \mathrm{F})$ was calculated as dose/AUC $\mathrm{A}_{0-\infty}$ after single dosing and as dose/AUC ${ }_{0-24}$ after multiple dosing. The apparent volume of distribution $\left(V_{\mathrm{z}} / F\right)$ during the terminal phase was calculated as $\mathrm{CL} / \mathrm{F} / \lambda_{\mathrm{z}}$. The accumulation ratio for $\mathrm{AUC}\left(\mathrm{RA}_{\mathrm{AUC}}\right)$ was calculated as $\mathrm{AUC}_{0-24(\text { Day } 13-14)} / \mathrm{AUC}_{0-24 \text { (Day 0-1) }}$. The accumulation ratio for maximum concentration $\left(\mathrm{RA}_{\mathrm{Cmax}}\right)$ was calculated as $C_{\max (\text { Day } 13-14)} / C_{\max (\text { Day 0-1) }}$. The amount of IMU-838 excreted in the urine in the given collection interval $\left(A_{\mathrm{e}}\right)$ was also calculated.

\subsubsection{Safety and Tolerability}

Safety and tolerability were assessed in both the studies by the clinical evaluation of adverse events (AEs), vital signs (blood pressure, pulse rate), 12-lead electrocardiogram (ECG), Holter ECG, physical examination and laboratory investigations (urine and plasma).

Table 2 MAD study design

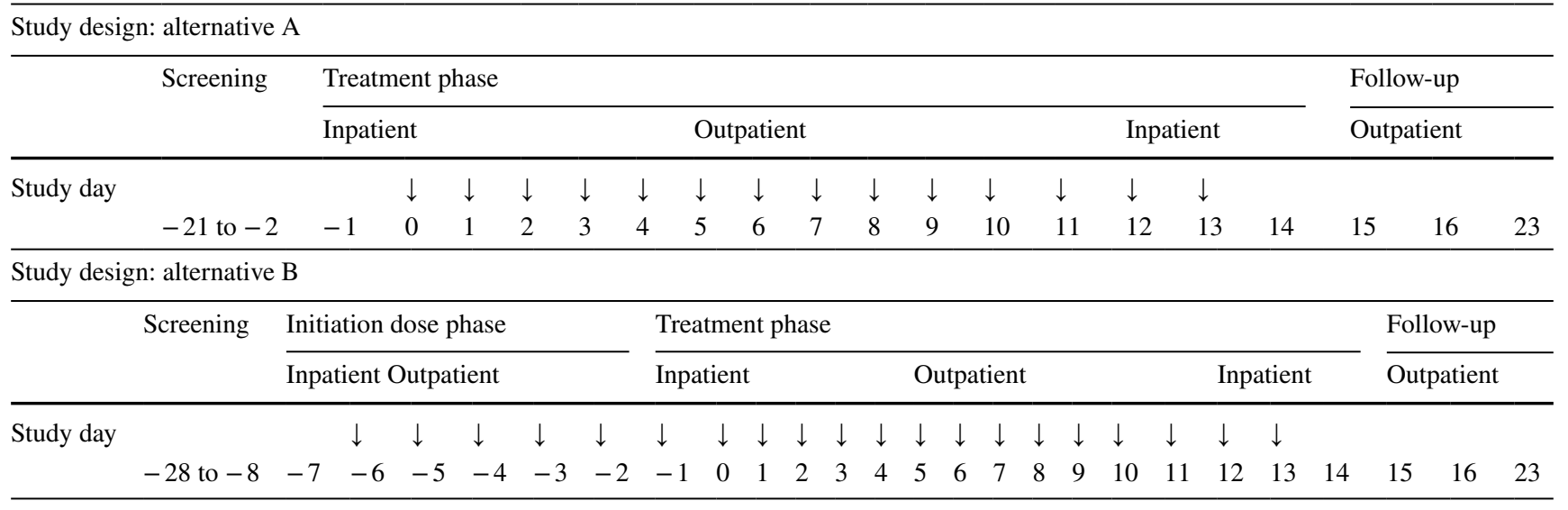

$\downarrow$ dosing, MAD multiple ascending dose 


\subsection{Population Pharmacokinetic Model}

A preliminary structural population pharmacokinetic model was evaluated based on available SAD and MAD data. Concentration data collected after administration in the fed state or collected after pre-dosing were not included. The outliers identified in the MAD study were included. The purpose was to evaluate the feasibility to fit a population pharmacokinetic model on phase 1 data to update it with data from future phase 2 studies.

A two-compartment model with first-order kinetic constants for absorption, inter-compartmental transfer and elimination was fitted on the IMU-838 concentrations after single (only doses in the fasted state) and multiple administration (Fig. 1). After visual inspection of the mean concentrationtime profiles in a semi-logarithmic scale (see Figs. 2, 3), it was concluded that a bi-exponential model was appropriate. The population pharmacokinetic model was parametrized in terms of absorption rate $(\mathrm{ka})$, volume $\left(V_{1} / F\right.$, volume in the central compartment and $V_{2} / F$, volume in the peripheral compartment) and clearance (CL/F, the apparent total clearance, and $Q / F$, the intercompartmental clearance between the central and peripheral compartments). The absorption rate was estimated by fitting the two-compartment population pharmacokinetic model on SAD and MAD data without any derivation. The elimination $\left(k_{10}\right)$ and inter-compartmental rate constants $\left(k_{12}, k_{21}\right)$ were derived from the clearance and volume as expressed below:

$$
\begin{aligned}
& k_{10}=\frac{\mathrm{CL} / F}{V_{1} / F} \\
& k_{12}=\frac{Q / F}{V_{1} / F} \\
& k_{21}=\frac{Q / F}{V_{2} / F}
\end{aligned}
$$

The alpha $t_{1 / 2}$ was the $t_{1 / 2}$ on the rapid distribution phase, and the beta $t_{1 / 2}$ was the $t_{1 / 2}$ on the slow elimination phase. Both alpha and beta $t_{1 / 2}$ were derived from the elimination and inter-compartmental rate constants.

In this preliminary stage, only the structural population pharmacokinetic model was estimated, without any covariate testing. Observations below the lower limit of quantitation (LLOQ; $<0.1 \mu \mathrm{g} / \mathrm{ml}$ ) were treated as left-censored data. Inter-individual variability (IIV) was estimated on CL/F and $V_{1} / F$ according to the following equation:

$P_{i}=\mathrm{TVP} \cdot \mathrm{e}^{\eta_{i}}$

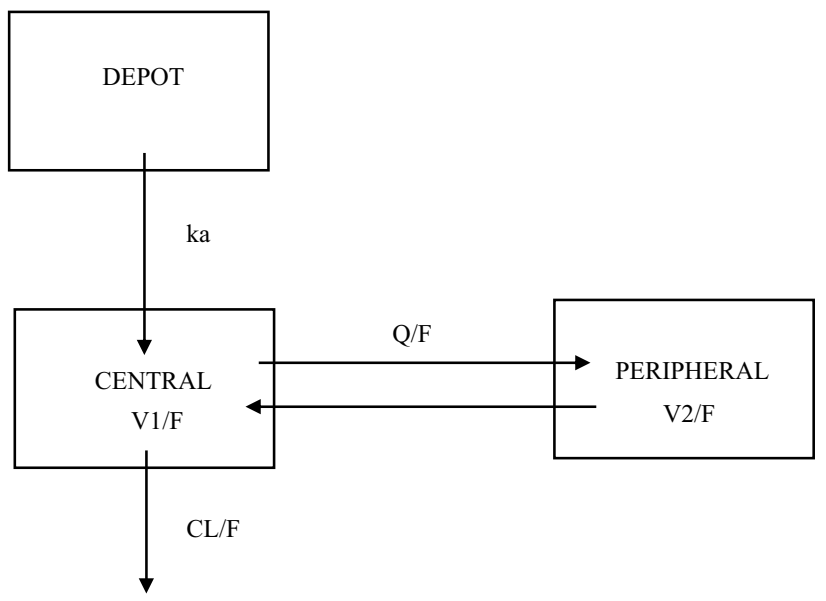

Fig. 1 Schematic representation of the two-compartment model. $C L / F$ apparent total clearance, $k a$ absorption rate, $Q / F$ intercompartmental clearance between central and peripheral compartments, $V_{1} / F$ volume in central compartment, $V_{2} / F$ volume in peripheral compartment

where $P_{i}$ is the estimated parameter for subject $i$, TVP is the typical population value of the parameter, and $\eta_{i}$ are individual-specific inter-individual random effects for individual $i$ and are assumed to be normally distributed, $\eta \sim N\left(0, \omega^{2}\right)$ with a variance-covariance matrix for the inter-individual random effects $(\Omega)$. Residual error was modeled using an exponential error model:

$Y_{i j}=\operatorname{IPRED}_{i j} \cdot \mathrm{e}^{\varepsilon_{i j}}$

where $Y$ is the observed concentration in the $i$ th individual at the $j$ th time point, individual predicted data (IPRED) is the individual predicted concentration in the $i$ th individual, and $\varepsilon$ is the residual error in the $i$ th individual at the $j$ th time point and is assumed to be normally distributed, $\varepsilon \sim N\left(0, \sigma^{2}\right)$ with $\sigma^{2}$ the residual variability.

\subsection{Statistical Analysis}

For SAD and MAD studies, the pharmacokinetic parameters of IMU-838 were assessed for dose proportionality. The respective linear regression model related the logarithm of dose as an independent variable to the logarithm of the pharmacokinetic parameters. To investigate dose proportionality, an estimate for the slope of the regression line with a $95 \%$ confidence interval was presented. A value that was appreciably different from 1 provided evidence for non-proportionality. All safety data were evaluated descriptively. The pharmacokinetic statistical analysis was conducted by using the computer software package SAS 9.4. The population pharmacokinetic analysis model was developed using 


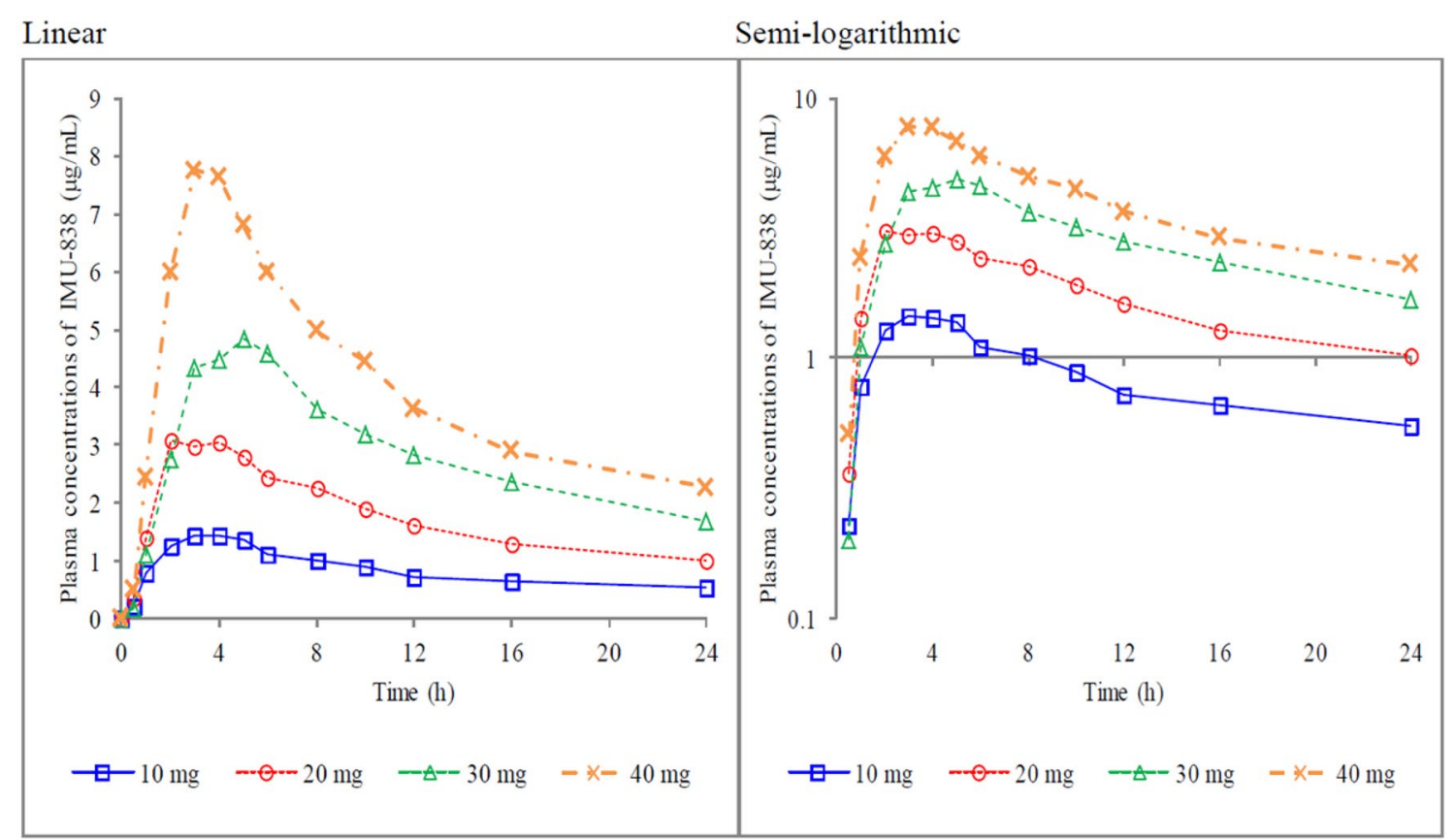

Fig. 2 Mean concentration-time profiles of IMU-838 (vidofludimus calcium) up to $24 \mathrm{~h}$ post-dose after fasted administration of IMU-838 in SAD study. $h$ hour, $S A D$ single ascending dose

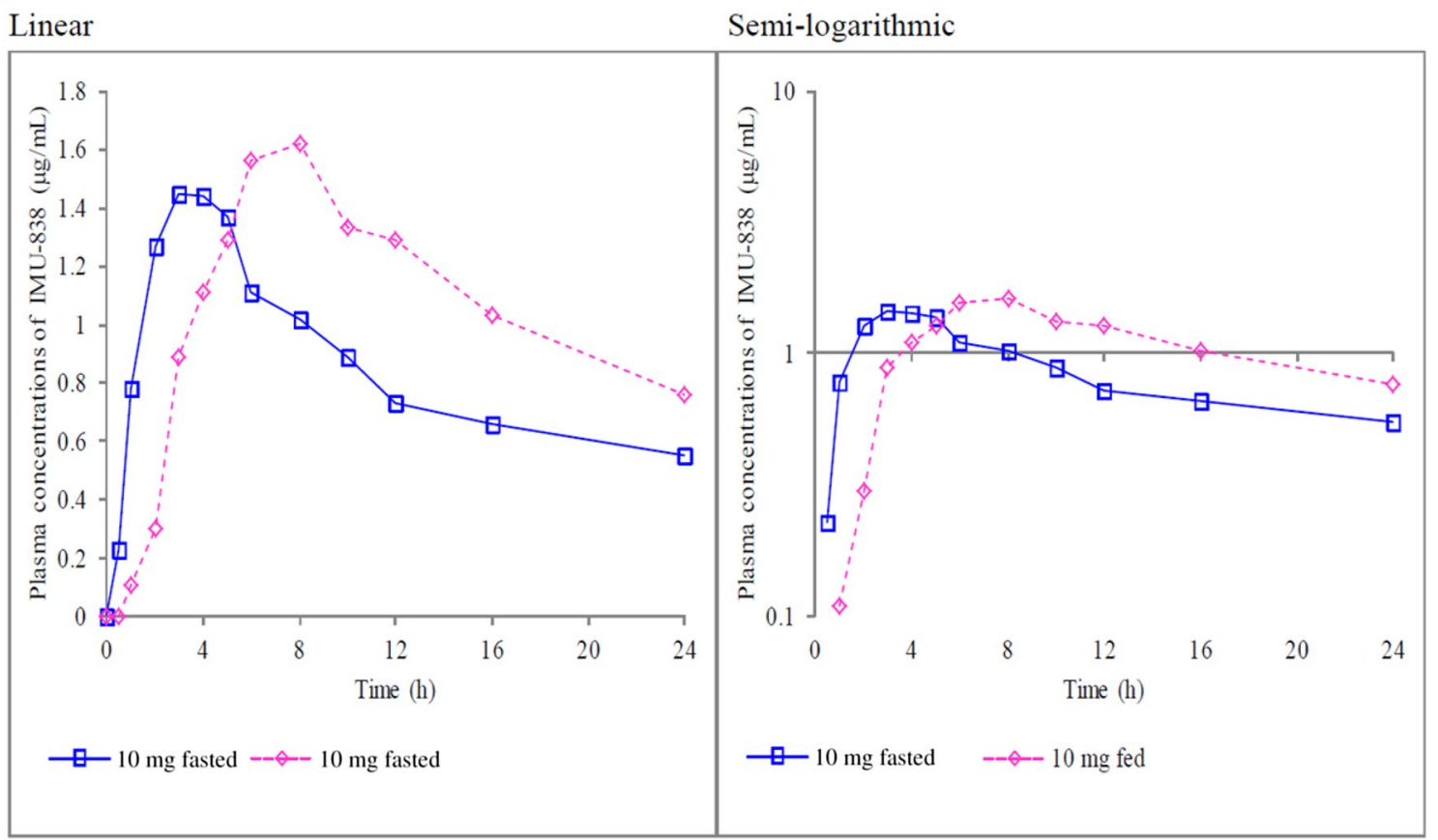

Fig. 3 Mean concentration-time profiles of IMU-838 (vidofludimus calcium) up to $24 \mathrm{~h}$ post-dose after fasted and fed administration of $10 \mathrm{mg}$ IMU-838 in the SAD study. $h$ hour, $S A D$ single ascending dose 
SAS 9.4 (SAS/STAT 15.1) with the PROC NLMIXED procedure in combination with the CMPTMODEL statement.

\section{Results}

\subsection{Pharmacokinetics}

\subsubsection{Study 1: SAD Study}

The inter-assay accuracy and precision data were calculated from 32 sets of QC samples. One set of QC samples consisted of three concentrations $(0.300,12.5$ and $20.0 \mu \mathrm{g} / \mathrm{ml})$. Each sequence contained two sets of QC samples (the prequalifying run six sets). The linearity (mean $r^{2}$ of the standard curves) was 0.99786 . Accuracy (bias \%) and precision (range \%) were between -4.6 and -1.8 and between 6.1 and 13.1, respectively. The precision and accuracy data are comparable to the results of the validation. Therefore, it can be concluded that the sample results are reliable within the given accuracy and precision ranges.

Mean concentration-time (linear and semilogarithmic) profiles of IMU-838 are summarized in Fig. 2 (fasted administration up to $24 \mathrm{~h}$ post-dose) and Fig. 3 (fasted-fed administration). All pre-dose concentrations were below the LLOQ $(<0.1 \mu \mathrm{g} / \mathrm{ml})$. Plasma concentrations rapidly increased dose dependently and reached a peak concentration between 2 and $5 \mathrm{~h}$. The mean concentration-time profiles of IMU-838 were similar after fasted and fed administration with slightly higher and later peak concentration after administration in the fed state compared with the fasted state.

Single oral dosing of IMU-838 in doses ranging from 10 to $40 \mathrm{mg}$ results in predictable, dose-linear plasma pharmacokinetics under fasted conditions. A dose proportional increase in AUC and $C_{\max }$ was observed for IMU-838 with slopes near 1 and $95 \%$ confidence intervals containing the ' 1 ' (except for $\mathrm{AUC}_{0-\mathrm{t}}$ where the $95 \%$ confidence intervals were slightly above 1) (Supplementary Appendix 2). Geometric mean $t_{1 / 2}$ under fasted conditions ranged from 26.6 to $41.4 \mathrm{~h}$. Geometric mean CL/F under fasted conditions $(3.48-4.22 \mathrm{ml} / \mathrm{min})$ and $V_{\mathrm{z}} / F(9.36$ to $12.48 \mathrm{~L}$ ) were similar for all doses. For the $30 \mathrm{mg}$ dose (the dose expected to be closest to an effective dose), the terminal plasma $t_{1 / 2}$ was approximately $40 \mathrm{~h}$, and median time to maximum plasma concentration $\left(t_{\max }\right)$ was seen at $5 \mathrm{~h}$. Based on single-dose pharmacokinetics, an accumulation ratio regarding exposure following multiple daily dosing close to 2 was expected. Comparing single dosing of $10 \mathrm{mg}$ under fasted and fed conditions, no detrimental effect of food intake and only a small difference between fasted and fed conditions were found consistent with the lipophilic characteristics of the active ingredient. Blood exposure was only slightly higher (about $32 \%$ ) after fed administration compared with fasted conditions. Geometric mean $C_{\max }$ was about $23 \%$ higher. Overall, median $t_{\max }$ following single oral doses of IMU-838 occurred between 3 and $5 \mathrm{~h}$ under fasted conditions and $7 \mathrm{~h}$ under fed conditions, consistent with a known delayed stomach emptying following food intake. The principal IMU-838 pharmacokinetic parameters are summarized in Table 3.

The amount of IMU-838 excreted in urine was very low; concentrations were below the LLOQ in all samples obtained after $10 \mathrm{mg}$ IMU-838 and in four of six samples after $20 \mathrm{mg}$ IMU-838. Following $30 \mathrm{mg}$ IMU-838 and $40 \mathrm{mg}$ IMU-838, drug urine concentrations were found to be above the LLOQ for four of six and four of the five subjects, respectively, and the amount of IMU-838 excreted in urine from 4 to $28 \mathrm{~h}$ post-dose ranged between 0.22 and $0.46 \mathrm{mg}$ after $30 \mathrm{mg}$ IMU-838 and between 0.42 and $0.52 \mathrm{mg}$ after $40 \mathrm{mg}$ IMU-838. This amounts to slightly more than $1 \%$ of the administered dose excreted in urine during this single $24 \mathrm{~h}$ time period.

\subsubsection{Study 2: MAD Study}

The inter-assay accuracy and precision data were calculated from 64 sets of QC samples. One set of QC samples consisted of three concentrations $(0.300,12.5$ and $20.0 \mu \mathrm{g} / \mathrm{ml})$. Each sequence contained two sets of QC samples (the prequalifying run six sets). The linearity (mean $r^{2}$ of the standard curves) was 0.99776 . Accuracy (bias \%) and precision (range \%) in the MAD study were between -5.6 and -4.0 and between 7.2 and 7.9, respectively. The precision and accuracy data are comparable to the results of the validation. Therefore, it can be concluded that the sample results are reliable within the given accuracy and precision ranges.

Repeated oral dosing of IMU-838 in doses ranging from 30 to $50 \mathrm{mg}$ resulted in dose-proportional plasma pharmacokinetics under fasted conditions (Figs. 4, 5).

On day 0 , mean concentration-time profiles of IMU-838 were lowest after administration of $30 \mathrm{mg}$, similar after $40 \mathrm{mg}$ and $50 \mathrm{mg}$ (not pre-dosed) and highest after $50 \mathrm{mg}$ pre-dosed with peak concentrations at 3-4 h after dosing. Geometric mean $\mathrm{AUC}_{0-\mathrm{t}}$ of IMU-838 increased from $51.1 \mu \mathrm{g} \cdot \mathrm{h} / \mathrm{ml}$ after $30 \mathrm{mg}$ to $71.7 \mu \mathrm{g} \cdot \mathrm{h} / \mathrm{ml}$ after $40 \mathrm{mg}$ and showed no further increase after administration of $50 \mathrm{mg}$ (not pre-dosed: $66.7 \mu \mathrm{g} \cdot \mathrm{h} / \mathrm{ml}$ ). Similar results were seen for $\mathrm{AUC}_{0-24 \mathrm{~h}}$. Geometric mean $C_{\max }$ of IMU-838 increased from $3.98 \mu \mathrm{g} / \mathrm{ml}$ after $30 \mathrm{mg}$ IMU-838 to $5.81 \mu \mathrm{g} / \mathrm{ml}$ after $40 \mathrm{mg}$ IMU-838; no further increase was observed after $50 \mathrm{mg}$ (not pre-dosed: $5.02 \mu \mathrm{g} / \mathrm{ml}$ ). Median $t_{\max }$ occurred between 2 and $3 \mathrm{~h}$. The $t_{1 / 2}, \mathrm{CL} / F$ and $V_{\mathrm{z}} / F$ could not be calculated after the single dose because of a too short observation period before the second dosing. 
Table 3 Summary of the main pharmacokinetic parameters of IMU-838 (vidofludimus calcium) in the SAD study

\begin{tabular}{llllll}
\hline Parameters & $10 \mathrm{mg}$ fasted $(n=6)$ & $20 \mathrm{mg}$ fasted $(n=6)$ & $30 \mathrm{mg}$ fasted $(n=6)$ & 40 mg fasted $(n=5)$ & $10 \mathrm{mg}$ fed $(n=6)$ \\
\hline $\mathrm{AUC}_{0-\mathrm{t}}(\mu \mathrm{g} \cdot \mathrm{h} / \mathrm{ml})$ & $35.749(16.3)$ & $72.973(17.1)$ & $129.785(31.4)$ & $180.809(18.4)$ & $47.441(30.1)$ \\
$\mathrm{AUC}_{0-24}(\mu \mathrm{g} \cdot \mathrm{h} / \mathrm{ml})$ & $19.663(22.9)$ & $41.107(19.4)$ & $64.521(34)$ & $94.413(17.4)$ & $24.199(29.9)$ \\
$\mathrm{AUC}_{0-\infty}(\mu \mathrm{g} \cdot \mathrm{h} / \mathrm{ml})$ & $41.010(15.9)$ & $79.023(17.2)$ & $137.617(29.3)$ & $191.565(21)$ & $53.941(25.5)$ \\
$C_{\max }(\mu \mathrm{g} / \mathrm{ml})$ & $1.527(33.7)$ & $3.374(25.6)$ & $4.943(57.1)$ & $7.856(21.2)$ & $1.881(36.3)$ \\
$t_{\max }(\mathrm{h})$ & $3.17(2-5)$ & $4.00(2-8)$ & $5.33(1-12)$ & $3.40(3-4)$ & $6.34(3-8)$ \\
$\mathrm{CL} / F(\mathrm{ml} / \mathrm{min})$ & $4.064(15.9)$ & $4.218(17.2)$ & $3.633(29.3)$ & $3.480(21)$ & $3.090(25.5)$ \\
$V_{\mathrm{z}} / F(\mathrm{l})$ & $9.362(13.5)$ & $10.238(23.0)$ & $12.398(27.3)$ & $12.485(19.6)$ & $9.018(23.7)$ \\
$t_{1 / 2}(\mathrm{~h})$ & $26.613(21.3)$ & $28.039(28.8)$ & $39.422(15.8)$ & $41.444(13.6)$ & $33.718(14.3)$ \\
\hline
\end{tabular}

Geometric mean (geometric \% CV) is reported above; for $t_{\text {max }}$, median (minimum-maximum) is reported

$A U C_{0-t}$ area under the plasma concentration-time curve from time 0 to the last time point with a detectable plasma concentration, $A U C_{0-24}$ area under the plasma concentration-time curve from time 0 to scheduled sample at time $24 \mathrm{~h}, A U C_{0-\infty}$ area under the plasma concentration-time curve from time 0 to infinity, $C L / F$ apparent total clearance, $C_{\max }$ maximum plasma concentration, $n$ number of subjects, $C V$ coefficient of variation, $t_{\max }$ time to maximum plasma concentration, $t_{1 / 2}$ half-life, $V_{z} / F$ apparent volume of distribution, $S A D$ single ascending dose

Steady-state concentrations were reached within about 6-8 days for the pre-dosed group as well as for the $30-50 \mathrm{mg}$ groups (Fig. 5). The median $t_{\max }$ following multiple oral doses of IMU-838 occurred between 2 to $3 \mathrm{~h}$ after the first and after repeated dosing (Table 4). Geometric mean $t_{1 / 2}$ at steady state ranged from 28.6 to $30.4 \mathrm{~h}$. After 14 days of dosing, geometric mean $\mathrm{AUC}_{0-\mathrm{t}}$ of IMU-838 was $189 \mathrm{~h} \cdot \mu \mathrm{g} /$ $\mathrm{ml}$ after $30 \mathrm{mg}, 285 \mathrm{~h} \cdot \mu \mathrm{g} / \mathrm{ml}$ after $40 \mathrm{mg}$ and similar after $50 \mathrm{mg} \mathrm{IMU}-838$ (304 and $310 \mathrm{~h} \cdot \mu \mathrm{g} / \mathrm{ml}$ ), independent of whether pre-dosed with half-dose IMU-838 or placebo. Similar differences between the treatments were seen for $\mathrm{AUC}_{0-24 \mathrm{~h}}$. Geometric mean $C_{\text {max }}$ of IMU-838 was $6.54 \mu \mathrm{g} /$ $\mathrm{ml}$ after $30 \mathrm{mg}$ IMU-838 and similar after $40 \mathrm{mg}$ and $50 \mathrm{mg}$ (10.9, 10.7 and $10.8 \mu \mathrm{g} / \mathrm{ml}$ after $40 \mathrm{mg}, 50 \mathrm{mg}$ pre-dosed and $50 \mathrm{mg}$ not pre-dosed, respectively). A dose-proportional increase in AUC and $C_{\max }$ was observed for IMU-838 with slopes near 1 and $95 \%$ confidence intervals containing the ' 1 ' (Supplementary Appendix 3). The accumulation factor after repeated dosing ranged between 1.96 to 2.49 for AUC $0-\mathrm{t}$ and 1.64 to 2.16 for $C_{\max }$.

\subsection{Safety}

Single oral doses of IMU-838 were well tolerated. A total of nine treatment-emergent AEs (TEAEs) were reported with the highest incidence of them found following the lowest single dose (10 mg IMU-838 fasted). No dose dependency was found regarding TEAEs. All TEAEs were of mild intensity and resolved within hours without treatment. Only three TEAEs (flatulence, micturition urgency and headache) experienced by three subjects were considered drug-related by the investigator (Table 5). Vital signs, ECG, physical examination and laboratory parameters did not reveal any clinically significant post-dose changes or differences between treatments. Particular emphasis was given to AEs of special interest that included hematuria and retroperitoneal colicky pain in connection with suspected or confirmed nephrolithiasis. Despite the close monitoring of these areas, no clinically significant laboratory findings of special interest and no AEs of special interest were observed.

Repeated daily oral doses of 30-50 mg IMU-838 administered once daily over 14 consecutive days were well tolerated. Overall, 79 TEAEs of mild or moderate intensity were reported by 31 subjects (59.6\%); overall, 53 TEAEs, reported by 29 subjects $(55.8 \%)$, were considered drug related. There was no increase in the number of subjects who reported drug-related TEAEs or in the number of drugrelated TEAEs with increasing dose. The rate of TEAEs was highest after dosing of $30 \mathrm{mg}$ IMU-838 [9 subjects (75.0\%) reported 18 drug-related TEAEs] and lower after dosing of $40 \mathrm{mg}$ IMU-838 (5 subjects [41.7\%] reported 8 drug-related TEAEs) and after $50 \mathrm{mg}$ IMU-838 (8 subjects [50.0\%] reported 16 drug-related TEAEs).

The most frequently reported drug-related TEAEs were flatulence, mainly observed after $30 \mathrm{mg}$ IMU-838, and hemoglobinuria (based solely on positive urine dipstick findings; only 1 of 9 positive findings of hemoglobinuria as measured by urine dipstick could be substantiated by urine sediment analysis) mainly observed after $50 \mathrm{mg}$ IMU-838. Other TEAEs considered drug related by the investigator and that were reported by more than a single subject per treatment were fatigue and headache (Table 6).

The majority of individual laboratory values were within the normal ranges. There were no clinically relevant differences between pre- and post-dose assessments and between the treatment groups for any parameter. Most deviations from the normal ranges in any laboratory parameter were small and considered not clinically relevant. Deviations in laboratory values considered possibly clinically relevant were recorded in five subjects (increase in gamma-glutamyl transferase [GGT], creatine kinase, blood glucose, lipase, and urine erythrocytes). Laboratory tests to check 

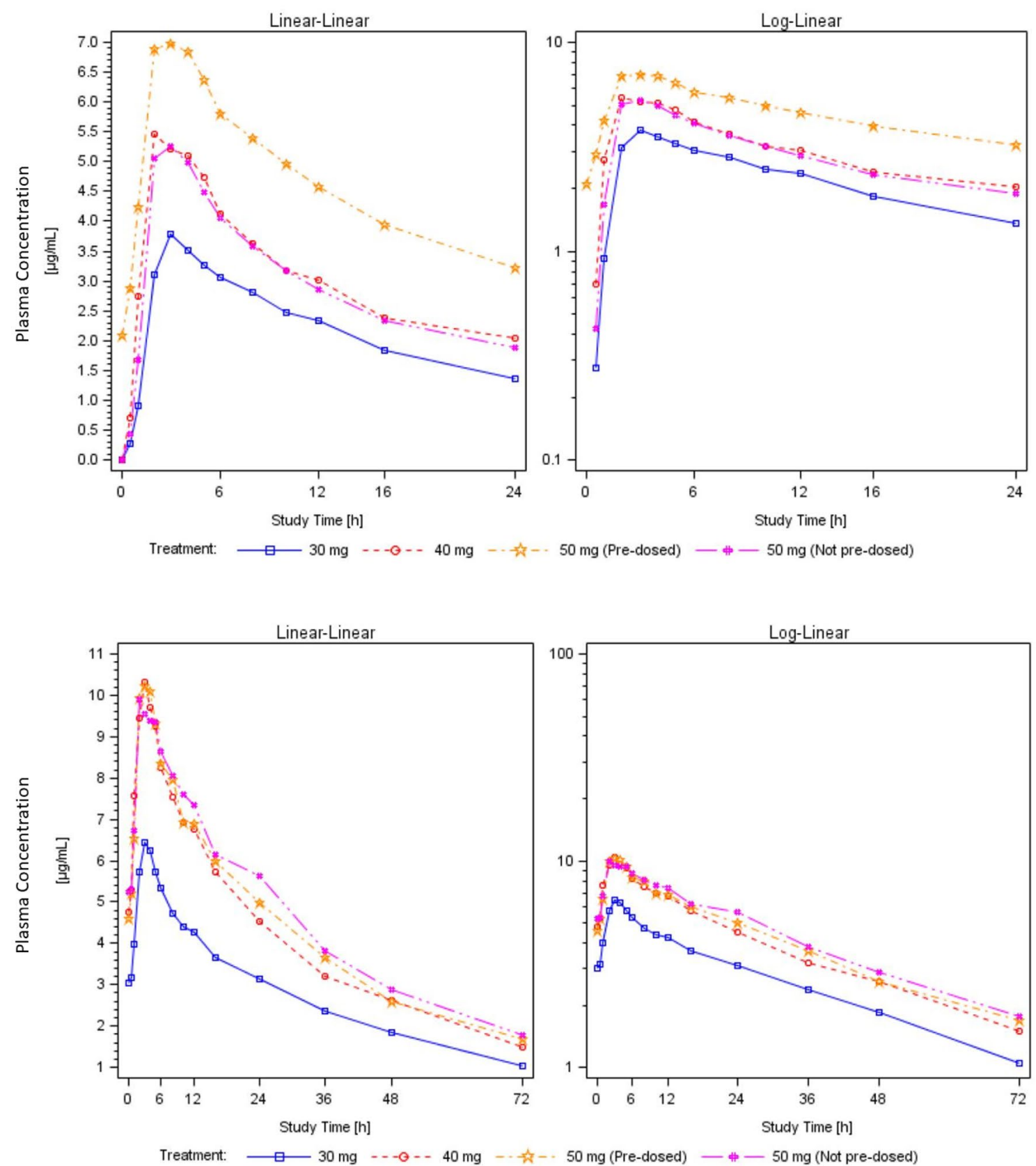

Fig. 4 Mean concentration time profiles of IMU-838 (vidofludimus calcium) up to $24 \mathrm{~h}$ after dosing on day 0 and up to $72 \mathrm{~h}$ after dosing on day 13 in MAD study. $h$ hour, MAD multiple ascending dose

liver function parameters (alanine aminotransferase [ALT], aspartate aminotransferase [AST], GGT, total bilirubin and direct/indirect bilirubin) resulted in a single clinically relevant abnormality in one subject only. Pre-treatment with a half-dose of IMU-838 was associated with a smaller increase of uric acid excreted in urine and to a smaller decrease in plasma oxalate upon the start of the 14-day treatment period compared with pre-dosing with placebo.
Physical examination, ECG and vital signs data showed no clinically significant findings except for 'suprapubic tenderness' and 'flank tenderness' in one subject (50 mg IMU838; without pre-dosing) and an 'atrioventricular block first degree' on day -5 in one subject ( $25 \mathrm{mg}$ IMU- 838 initiation dosing); no further abnormal ECG findings were observed for this subject, even when the dose was increased to $50 \mathrm{mg}$ for 14-day treatment between day 0 and day 13. One single event of moderate hematuria was observed at the end of the 


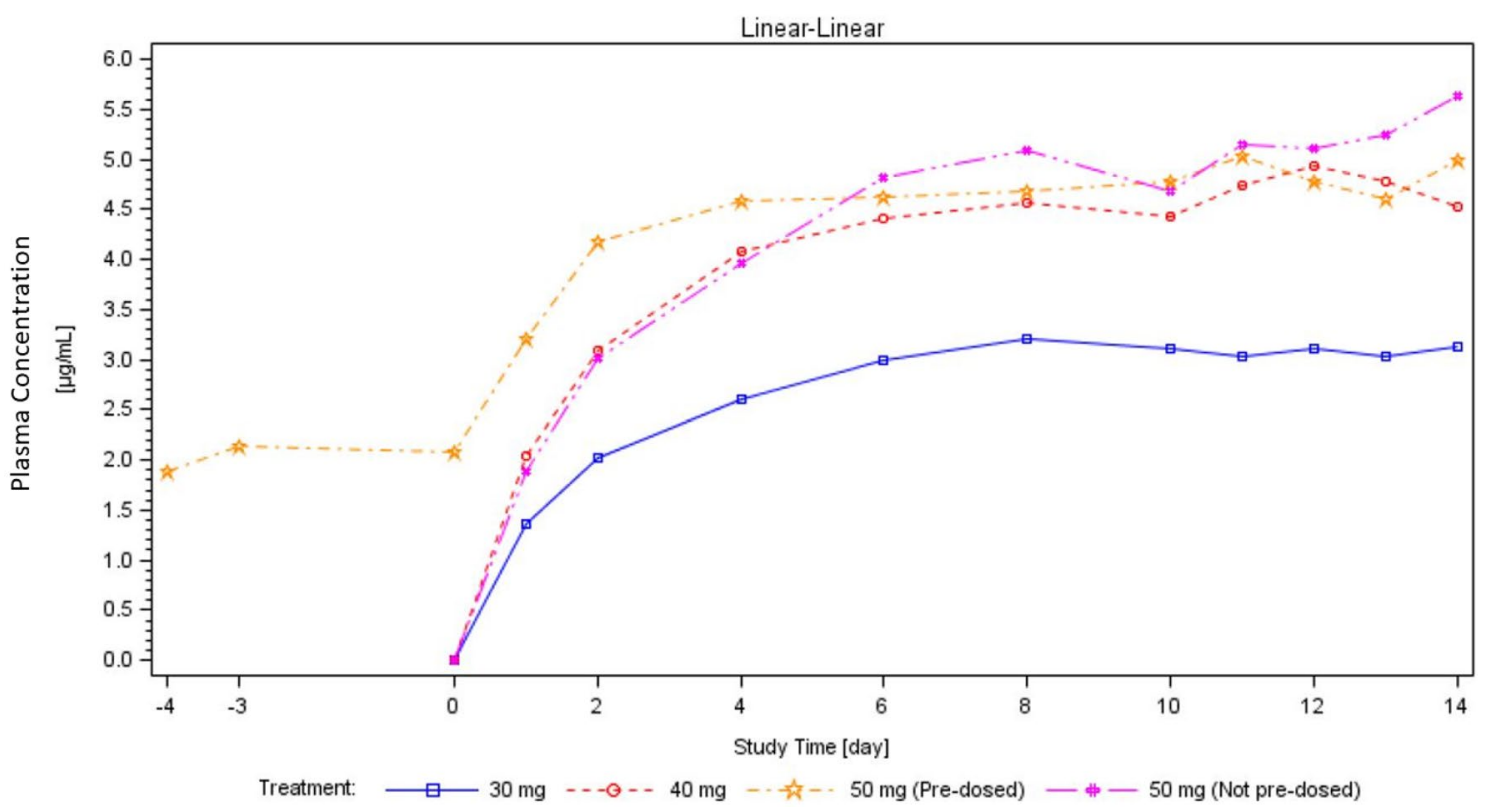

Fig. 5 Mean trough plasma concentration time profiles of the IMU-838 (vidofludimus calcium) in MAD study. MAD multiple ascending dose

Table 4 Summary of the main pharmacokinetic parameters of IMU-838 (vidofludimus calcium) in MAD study

\begin{tabular}{|c|c|c|c|c|c|}
\hline Parameters & $30 \mathrm{mg}(n=12)$ & $40 \mathrm{mg}(n=12)$ & $50 \mathrm{mg}$ pre-dosed $(n=8)$ & $\begin{array}{l}50 \mathrm{mg} \text { not pre- } \\
\text { dosed }(n=8)\end{array}$ & $50 \mathrm{mg}$ all $(n=16)$ \\
\hline \multicolumn{6}{|l|}{ Day 0} \\
\hline $\mathrm{AUC}_{0-24}(\mu \mathrm{g} \bullet \mathrm{h} / \mathrm{ml})$ & $51.211(29.0)$ & $78.315^{\mathrm{a}}(25.6)$ & $107.440^{\mathrm{b}}(28.0)$ & $67.143(36.7)$ & $82.130^{c}(41.0)$ \\
\hline$C_{\max }(\mu \mathrm{g} / \mathrm{ml})$ & $3.979(39.5)$ & $5.805(32.3)$ & $7.264(27.7)$ & $5.016(51.1)$ & $6.036(44.3)$ \\
\hline$t_{\max }(\mathrm{h})$ & $3.00(2.0-8.0)$ & $3.00(2.0-5.0)$ & $2.00(2.0-4.0)$ & $3.00(2.0-4.0)$ & $2.00(2.0-4.0)$ \\
\hline \multicolumn{6}{|l|}{ Day 13} \\
\hline $\mathrm{AUC}_{0-\mathrm{t}}(\mu \mathrm{g} \cdot \mathrm{h} / \mathrm{ml})$ & $188.554(30.3)$ & $284.959(25.3)$ & $304.154(16.1)$ & $310.301(32.7)$ & $307.212(24.8)$ \\
\hline $\mathrm{AUC}_{0-24}(\mu \mathrm{g} \cdot \mathrm{h} / \mathrm{ml})$ & $100.294(25.0)$ & $158.686(22.6)$ & $165.552(14.1)$ & $167.254(27.3)$ & $166.401(20.9)$ \\
\hline$C_{\max }(\mu \mathrm{g} / \mathrm{ml})$ & $6.543(25.8)$ & $10.911(20.2)$ & $10.725(20.1)$ & $10.841(21.5)$ & $10.783(20.1)$ \\
\hline$t_{\max }(\mathrm{h})$ & $3.00(3.0-12.0)$ & $3.00(1.0-5.0)$ & $3.00(2.0-5.0)$ & $2.00(2.0-5.0)$ & $2.50(2.0-5.0)$ \\
\hline $\mathrm{CL} / F(\mathrm{ml} / \mathrm{min})$ & $4.985(25.0)$ & $4.201(22.6)$ & $5.034(14.1)$ & $4.982(27.3)$ & $5.008(20.9)$ \\
\hline$V_{\mathrm{z}} / F(1)$ & $13.125(25.1)$ & $10.235^{\mathrm{d}}(17.0)$ & $13.040(19.4)$ & $12.802(23.5)$ & $12.920(20.8)$ \\
\hline $\mathrm{RA}_{\mathrm{AUC}}$ & $1.958(24.4)$ & $2.077^{\mathrm{e}}(23.1)$ & $1.584^{\mathrm{f}}(30.6)$ & $2.491(28.1)$ & $2.052^{\mathrm{g}}(37.1)$ \\
\hline $\mathrm{RA}_{C \max }$ & $1.644(37.6)$ & $1.880(30.1)$ & $1.476(38.7)$ & $2.161(48.8)$ & $1.786(47.5)$ \\
\hline$t_{1 / 2}(\mathrm{~h})$ & $30.414(20.5)$ & $28.566^{\mathrm{d}}(14.6)$ & $29.928(14.5)$ & $29.682(19.5)$ & 29.805 (16.6) \\
\hline
\end{tabular}

$A U C_{0-t}$ area under the plasma concentration-time curve from time 0 to the last time point with a detectable plasma concentration, $A U C_{0-24}$ area under the plasma concentration-time curve from time 0 to the scheduled sample at time $24 \mathrm{~h}, A U C_{0-\infty}$ area under the plasma concentration-time curve from time 0 to infinity, $C L / F$ apparent total clearance, $C_{\max }$ maximum plasma concentration, $n$ number of subjects, $C V$ coefficient of variation, $R A A U C$ accumulation ratio for $\mathrm{AUC}_{0-24}, R A_{C \max }$ accumulation ratio for $\mathrm{C}_{\max }, t_{\max }$ time to maximum plasma concentration, $t_{1 / 2}$ half-life, $V \_F$ apparent volume of distribution, $M A D$ multiple ascending dose

Geometric mean (geometric \%CV) is reported above; For $t_{\max }$, median (minimum-maximum) is reported; ${ }^{\mathrm{a}} n=9,{ }^{\mathrm{b}} n=6,{ }^{\mathrm{c}} n=14,{ }^{\mathrm{d}} n=11,{ }^{\mathrm{e}} n=9$, ${ }^{\mathrm{f}} n=6,{ }^{\mathrm{g}} n=14$; not calculated: not reliable because of high $\% \mathrm{AUC}_{\text {extrap }}$

dosing period with $50 \mathrm{mg}$ IMU-838, which was considered drug related, although this event was seen in a subject with clinical suspicion of urinary tract infection, which may be an alternative cause of this event. This event occurred in a subject that had been pre-dosed with placebo. 
Table 5 Treatment-emergent adverse events (TEAEs) in the SAD study

\begin{tabular}{|c|c|c|c|c|c|c|}
\hline \multirow[t]{3}{*}{ System organ class } & \multirow[t]{3}{*}{ Preferred term } & \multicolumn{5}{|l|}{ Treatment } \\
\hline & & $10 \mathrm{mg}$ fasted, $n=6$ & $20 \mathrm{mg}$ fasted, $n=6$ & $30 \mathrm{mg}$ fasted, $n=6$ & $40 \mathrm{mg}$ fasted, $n=5$ & $10 \mathrm{mg}$ fed, $n=6$ \\
\hline & & \multicolumn{5}{|c|}{$N(\%)$ [number of events] } \\
\hline Total & & $3(50.0)[5]$ & $1(16.7)[1]$ & $1(16.7)[1]$ & $1(20.0)[1]$ & $1(16.7)[1]$ \\
\hline \multirow[t]{2}{*}{$\begin{array}{l}\text { Infections and infes- } \\
\text { tations }\end{array}$} & $\begin{array}{l}\text { Viral upper } \\
\text { respiratory tract } \\
\text { infection }\end{array}$ & $2(33.3)[2]$ & - & - & - & - \\
\hline & Rhinitis & - & - & - & $1(20.0)[1]$ & - \\
\hline $\begin{array}{l}\text { Nervous system } \\
\text { disorders }\end{array}$ & Headache & $1(16.7)[1]$ & $1(16.7)[1]$ & - & - & - \\
\hline $\begin{array}{l}\text { Gastrointestinal } \\
\text { disorders }\end{array}$ & Flatulence & 1 (16.7) [1] & - & - & - & - \\
\hline Investigations & Opiates positive & - & - & $1(16.7)[1]$ & - & - \\
\hline $\begin{array}{l}\text { Renal and urinary } \\
\text { disorders }\end{array}$ & Micturition urgency & 1 (16.7) [1] & - & - & - & - \\
\hline $\begin{array}{l}\text { Respiratory, thoracic } \\
\text { and mediastinal } \\
\text { disorders }\end{array}$ & Epistaxis & - & - & - & - & $1(16.7)[1]$ \\
\hline
\end{tabular}

Bold: TEAEs considered drug-related, $N$ number of subjects having the event, $S A D$ single ascending dose

\subsection{Population Pharmacokinetic Model}

Pharmacokinetic parameters estimates with their relative standard error (\%RSE) are presented in Table 7. To check the goodness of fit, the predictive interval is presented in Fig. 6 (SAD study) and Fig. 7 (MAD study) with the observed concentration-time profiles. Based on the predictive intervals, the two-compartment pharmacokinetic model appears to appropriately describe the observed plasma concentration-time profiles.

\section{Discussion}

This phase 1, SAD and MAD clinical study characterized the safety, tolerability, and pharmacokinetic characteristics of IMU-838, an investigational oral selective immunomodulatory drug, in healthy male subjects. IMU-838 is a novel orally available drug that inhibits the intracellular metabolism of activated immune cells by blocking the enzyme DHODH. IMU-838 acts on activated T and B cells without affecting other immune cells, which allows the immune system to keep functioning.

The aim of the SAD and MAD study was to assess the pharmacokinetics of IMU-838 (in particular plasma concentrations). A partial parallel design with a small number of healthy male subjects aged 18-55 years was considered appropriate for the clinical studies given the safety database of 299 subjects previously exposed to vidofludimus (free acid) and 12 subjects to IMU-838 (vidofludimus calcium in the SAD study) and given the fact that only doses were used that were well below the doses at which the first AEs of special interest (red blood cells [RBCs] in urine or hematuria) were expected. In the previous phase $1 \mathrm{SAD}$ trial of vidofludimus (free acid), the lowest single dose at which hematuria was present was $210 \mathrm{mg}$. As the monitoring of erythrocytes in urine was a major safety objective in this trial, no female subjects were included as it is known that menses can serve as an alternative cause for hematuria. It was also important to evaluate the blood exposure of IMU-838 comparing fasted and fed conditions for future trials that will use multiple doses (the expected form of therapy for IMU-838). The inclusion of a fed/fasted arm was considered important for the treatment regimen in a consecutively planned multipledose study. The partial parallel group design would allow intra-individual comparison of fasted and fed conditions in the one-dose group (10 mg).

IMU-838 was readily absorbed following administration of single oral doses under fasted condition. Single oral doses of 10-40 mg of IMU-838 under fasted conditions were associated with a dose-proportional increase in AUC and $C_{\max }$ with slopes near 1 and $95 \%$ confidence intervals containing the ' 1 ' (except for $\mathrm{AUC}_{0-\mathrm{t}}$, where the $95 \%$ confidence intervals were slightly $>1$ ). The geometric mean $t_{1 / 2}$ ranged from about 27 to $41 \mathrm{~h}$, and the median $t_{\max }$ occurred between 3 and $5 \mathrm{~h}$. Geometric mean CL/F and $V_{\mathrm{z}} / F$ were similar for all doses. Food intake was not associated with any detrimental effect on IMU-838 exposure, which was found consistent 
Table 6 Treatment-emergent adverse events (TEAEs) in the MAD study

\begin{tabular}{|c|c|c|c|c|c|c|}
\hline \multirow[t]{3}{*}{ System organ class } & \multirow[t]{3}{*}{ Preferred term } & \multicolumn{5}{|l|}{ Treatment } \\
\hline & & $25 \mathrm{mg}, n=8^{\mathrm{b}}$ & $30 \mathrm{mg}, n=12$ & $40 \mathrm{mg}, n=12$ & $50 \mathrm{mg}, n=16^{\mathrm{b}}$ & Placebo, $n=20^{\mathrm{b}}$ \\
\hline & & \multicolumn{5}{|c|}{$N(\%)$ [number of events] } \\
\hline Total & & $3(37.5)[4]$ & $9(75.0)[20]$ & $6(50.0)[12]$ & $10(62.5)[22]$ & $9(45.0)[21]$ \\
\hline \multirow[t]{8}{*}{ Gastrointestinal disorders } & Total & $1(12.5)[2]$ & $7(58.3)[14]$ & $1(8.3)[1]$ & $2(12.5)[3]$ & $3(15.0)[5]$ \\
\hline & Abdominal pain & - & $1(8.3)[1]$ & - & - & - \\
\hline & Abdominal pain upper & 1 (12.5) [1] & - & - & $1(6.3)[2]$ & - \\
\hline & Diarrhea & 1 (12.5) [1] & - & - & - & $1(5.0)[1]$ \\
\hline & Dyspepsia & - & - & - & $1(6.3)[1]$ & $1(5.0)[1]$ \\
\hline & Feces soft & - & $2(16.7)[2]$ & - & - & $1(5.0)[1]$ \\
\hline & Flatulence & - & $6(50.0)\left[10^{\mathrm{a}}\right]$ & $1(8.3)[1]$ & - & $1(5.0)[2]$ \\
\hline & Nausea & - & $1(8.3)[1]$ & - & - & - \\
\hline \multirow[t]{5}{*}{ Renal and urinary disorders } & Total & - & $1(8.3)[1]$ & $2(16.7)[2]$ & $6(37.5)[8]$ & $2(10.0)[3]$ \\
\hline & Dysuria & - & - & - & $1(6.3)[1]$ & - \\
\hline & Glycosuria & - & - & - & - & $1(5.0)[2]$ \\
\hline & Hematuria & - & - & - & $1(6.3)[1]$ & - \\
\hline & Hemoglobinuria $^{c}$ & - & $1(8.3)[1]$ & 2 (16.7) [2] & $5(31.3)\left[6^{\mathrm{a}}\right]$ & $1(5.0)[1]$ \\
\hline \multirow[t]{3}{*}{ Infections and infestations } & Total & $1(12.5)[1]$ & - & - & $4(25.0)[4]$ & $5(25.0)[6]$ \\
\hline & Nasopharyngitis & $1(12.5)[1]$ & - & - & $4(25.0)[4]$ & $5(25.0)[5]$ \\
\hline & Rhinitis & - & - & - & - & $1(5.0)[1]$ \\
\hline \multirow{3}{*}{$\begin{array}{l}\text { General disorders and administra- } \\
\text { tion site conditions }\end{array}$} & Total & - & - & $3(25.0)[3]$ & $1(6.3)[1]$ & $1(5.0)[1]$ \\
\hline & Fatigue & - & - & $3(25.0)\left[3^{a}\right]$ & - & $1(5.0)[1]$ \\
\hline & Tenderness & - & - & - & $1(6.3)[1]$ & - \\
\hline \multirow[t]{2}{*}{ Nervous system disorders } & Total & - & $1(8.3)[1]$ & $1(8.3)[2]$ & $3(18.8)[3]$ & $1(5.0)[1]$ \\
\hline & Headache & - & $1(8.3)[1]$ & $1(8.3)[2]$ & $3(18.8)[3]$ & $1(5.0)[1]$ \\
\hline \multirow[t]{5}{*}{ Investigations } & Total & - & $2(16.7)[3]$ & $1(8.3)[1]$ & $1(6.3)[1]$ & $1(5.0)[1]$ \\
\hline & Blood creatinine kinase increased & - & - & $1(8.3)[1]$ & - & - \\
\hline & Blood glucose increased & - & - & - & - & $1(5.0)[1]$ \\
\hline & $\begin{array}{l}\text { Gamma-glutamyl transferase } \\
\text { increased }\end{array}$ & - & $1(8.3)[2]$ & - & - & - \\
\hline & Lipase increased & - & $1(8.3)[1]$ & - & $1(6.3)[1]$ & - \\
\hline \multirow{5}{*}{$\begin{array}{l}\text { Musculoskeletal and connective } \\
\text { tissue disorders }\end{array}$} & Total & - & $1(8.3)[1]$ & - & $1(6.3)[1]$ & $3(15.0)[4]$ \\
\hline & Back pain & - & - & - & - & $1(5.0)[1]$ \\
\hline & Flank pain & - & - & - & $1(6.3)[1]$ & $1(5.0)[1]$ \\
\hline & Musculoskeletal discomfort & - & $1(8.3)[1]$ & - & - & - \\
\hline & Pain in extremities & - & - & - & - & $2(10.0)[2]$ \\
\hline \multirow{3}{*}{$\begin{array}{l}\text { Respiratory, thoracic and mediasti- } \\
\text { nal disorders }\end{array}$} & Total & - & - & $1(8.3)[1]$ & $1(6.3)[1]$ & - \\
\hline & Epistaxis & - & - & - & $1(6.3)[1]$ & - \\
\hline & Sneezing & - & - & $1(8.3)[1]$ & - & - \\
\hline \multirow[t]{2}{*}{ Cardiac disorders } & Total & $1(12.5)[1]$ & - & - & - & - \\
\hline & Atrioventricular block first degree & 1 (12.5) [1] & - & - & - & - \\
\hline \multirow{2}{*}{$\begin{array}{l}\text { Injury, poisoning and procedural } \\
\text { complications }\end{array}$} & total & - & - & $1(8.3)[1]$ & - & - \\
\hline & Arthropod bite & - & - & $1(8.3)[1]$ & - & - \\
\hline \multirow[t]{2}{*}{ Psychiatric disorders } & Total & - & - & $1(8.3)[1]$ & - & - \\
\hline & Listless & - & - & $1(8.3)[1]$ & - & - \\
\hline
\end{tabular}

Bold: TEAEs considered drug-related, $N$ number of subjects having the event, $M A D$ multiple ascending dose

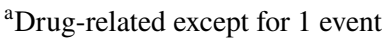

${ }^{\mathrm{b}}$ Multiple counting of the same subject in different treatment periods possible (dose group 3; $25 \mathrm{mg}, 50 \mathrm{mg}$ and placebo)

${ }^{\mathrm{c}}$ All occurrences of this AE were based solely on a positive dip stick test. The protocol had specified that evaluation of RBC in urine should be based solely on findings from microscopic examination of urinary sediment and not from dipstick reading alone. However, none of these positive dipstick readings were confirmed by a microscopic examination of urinary sediment. The investigator had decided to report these positive dipstick readings (without confirmation by urine sediment) as adverse events to provide a conservative reporting of events, even though this reporting was not protocol compliant 
Table 7 Population pharmacokinetic parameter estimates for the IMU-838 (vidofludimus calcium) base model

\begin{tabular}{llll}
\hline Parameter & Units & Estimate & $\% \mathrm{RSE}$ \\
\hline $\mathrm{CL} / F$ & $\mathrm{ml} / \mathrm{min}$ & 4.47 & 3.01 \\
$Q / F$ & $\mathrm{ml} / \mathrm{min}$ & 6.15 & 8.42 \\
$V_{1} / F$ & 1 & 2.98 & 17.3 \\
$V_{2} / F$ & 1 & 6.31 & 4.90 \\
$\mathrm{ka}$ & $\mathrm{h}^{-1}$ & 0.15 & 15.6 \\
$k_{10}$ & $\mathrm{~h}^{-1}$ & 0.0901 & 17.1 \\
$k_{12}$ & $\mathrm{~h}^{-1}$ & 0.124 & 14.3 \\
$k_{21}$ & $\mathrm{~h}^{-1}$ & 0.0584 & 10.6 \\
$t_{1 / 2}$ alpha & $\mathrm{h}$ & 2.76 & 11.5 \\
$t_{1 / 2}$ beta & $\mathrm{h}$ & 33.1 & 3.92 \\
IIV on CL/F & $\% \mathrm{CV}$ & 20.8 & 11.0 \\
IIV on V1/F & $\% \mathrm{CV}$ & 49.4 & 13.3 \\
Correlation coefficient IIV & - & 0.387 & 36.6 \\
$\quad$ CL/F and IIV $V 1 / F$ & & & \\
Exponential residual error & $\% \mathrm{CV}$ & 41.6 & 2.04 \\
\hline
\end{tabular}

$C L / F$ apparent total clearance, $C V$ coefficient of variation, $I I V$ interindividual variability, $k_{10}$ elimination rate constants, $k_{12}$ and $k_{21}$ intercompartmental rate constants, $k a$ absorption rate, $Q / F$ intercompartmental clearance between central and peripheral compartments, $V_{l} / F$ volume in central compartment, $V_{2} / F$ volume in peripheral compartment

$k_{10}$ was derived from the clearance and volume as per Eq. 1, $k_{12}$ and $k_{21}$ were derived from the clearance and volume as per Eqs. 2 and 3, respectively; IIV was estimated on $\mathrm{CL} / \mathrm{F}$ and $V_{1} / F$ as per Eq. 4; residual error was modeled using an exponential error model as per Eq. 5

with the lipophilic characteristics of the active ingredient. IMU-838 $t_{\max }$ was prolonged when given with food, consistent with a known delayed stomach emptying following food intake.

Multiple daily oral dosing of IMU-838 resulted in a dose linear plasma pharmacokinetics under fasted conditions up to doses of $50 \mathrm{mg}$ IMU-838. Geometric mean $\mathrm{t}_{1 / 2}$ at steady state ranged from 28.6 to $30.4 \mathrm{~h}$; median $t_{\max }$ occurred between 2 to $3 \mathrm{~h}$. These pharmacokinetic properties make IMU-838 well suited for once-daily dosing and limit the accumulation after repeat dosing (the accumulation factor ranged between 1.96 and 2.49 for $\mathrm{AUC}_{0-\mathrm{t}}$ and between 1.64 and 2.16 for $C_{\max }$ ). Steady-state concentrations were reached within about 6-8 days. The time needed to reach $97 \%$ of the steady state is at least 5 half-lives, meaning that at least $150 \mathrm{~h}$ (or 6.25 days) are needed to reach steady state. For the pre-dosed group, samples at $-2 \mathrm{~h}$ and $-1 \mathrm{~h}$ had not been planned; however, the mean concentration at time $0 \mathrm{~h}$ was about $50 \%$ of the concentration for the $50 \mathrm{mg}$ group at $6 \mathrm{~h}$ after repeated dosing on day 6 . Thus, linear pharmacokinetics can be assumed. The mean apparent terminal $\mathrm{t}_{1 / 2}$ calculated on day 13 was about $30 \mathrm{~h}$. The time needed to reach $97 \%$ of the steady state is at least five half-lives, meaning that at least $150 \mathrm{~h}$ (or 6.25 days) is needed to reach steady state.

Oral IMU-838 administered in single and multiple doses was well tolerated. There were no deaths or serious AEs reported in the study. All TEAEs were of mild or moderate intensity. There was no discontinuation in either the SAD and MAD study due to TEAEs. One subject in the SAD study prematurely discontinued the study for personal reasons. With the single doses, there were a total of nine TEAEs with the highest incidence found following the lowest single dose (10 mg IMU-838 fasted). With multiple doses, there were a total of 53 drug-related TEAEs with the highest incidence found following the lowest multiple dose (30 mg IMU-838). No dose dependency was found regarding TEAEs. Vital signs, physical examination and ECG parameters did not reveal any clinically significant post-dose changes or differences between treatments. The incidences of TEAEs for the $50 \mathrm{mg}$ dose group were similar between $25 \mathrm{mg}$ IMU-838 pre-treatment (6 days pre-treatment) and placebo pre-treatment. A smaller increase of uric acid excreted in urine and a smaller decrease in plasma oxalate upon the start of the 14-day treatment period were observed compared to pre-dosing with placebo. Thus, pre-dosing with a half-dose may be an effective strategy to further limit the risk of AEs of elevated RBC levels in urine or hematuria. Particular emphasis in this trial was given to AEs of special interest that included hematuria and retroperitoneal colicky pain in connection with suspected or confirmed nephrolithiasis. Moderate hematuria was observed at the end of the dosing period in a subject with $50 \mathrm{mg}$ IMU-838. This event was considered drug-related, although this event was seen in a subject with clinical suspicion of urinary tract infection, which was considered to be an alternative cause of this event.

A preliminary structural population pharmacokinetic model has been developed based on single- and multipledose concentration data collected after administration in the fasted state and without pre-dosing. A two-compartment pharmacokinetic model with first-order kinetic constants appears to appropriately describe the observed plasma concentration-time profiles. 
Fig. 6 Concentration-time profiles of IMU-838 (vidofludimus calcium) in the SAD study with the predictive interval of the population pharmacokinetic model (median, quantile $2.5 \%$ and quantile $97.5 \%$ ). SAD single ascending dose

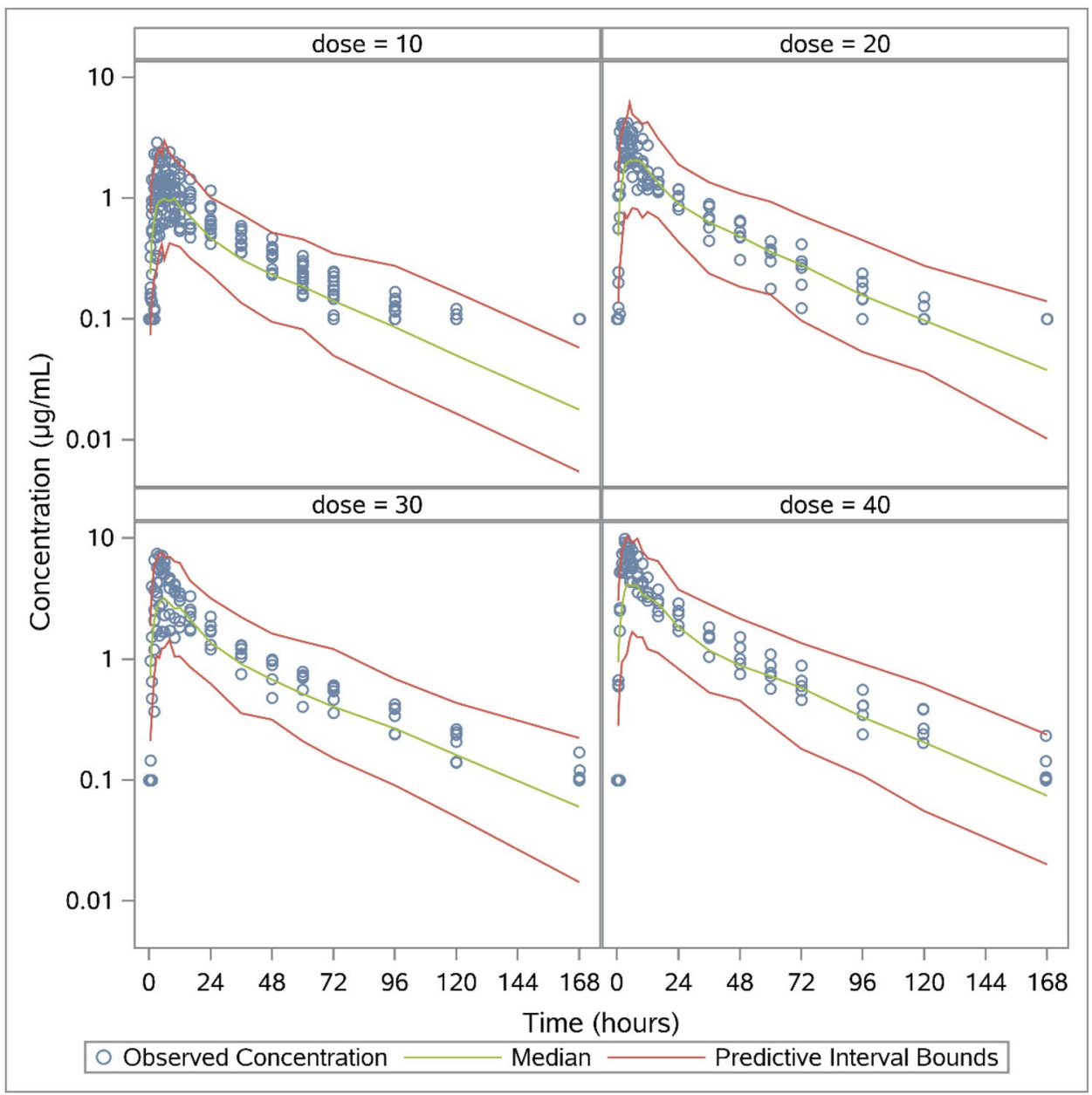

The present studies have several limitations: (1) first, the study is limited to Caucasian participants; (2) second, no women were studied because of the focus on monitoring hematuria; (3) third, as the main elimination pathway of IMU-838 seems to be biliary, the pharmacokinetics and elimination in patients with hepatic impairment remain to be explored.

\section{Conclusions}

Overall, oral IMU-838 was generally well tolerated in SAD and MAD studies in healthy subjects over a wide dose range of $10-50 \mathrm{mg}$. IMU-838 was well absorbed after single daily doses. IMU-838 showed dose-proportional pharmacokinetics after single and multiple oral dosing. Food did not impact the pharmacokinetics of IMU-838. Geometric mean plasma $\mathrm{t}_{1 / 2}$ of IMU-838 at steady state was approximately $30 \mathrm{~h}$, which supports its use for a once-daily dosing regimen that is currently being evaluated in phase 2 studies. A preliminary population pharmacokinetic model has been developed to support the further analysis of sparse pharmacokinetic data planned to be collected in the future phase 2 studies. 
Fig. 7 Concentration-time profiles of IMU-838 (vidofludimus calcium) in the MAD study with the predictive interval of the population pharmacokinetic model (median, quantile $2.5 \%$ and quantile $97.5 \%)$. MAD multiple ascending dose

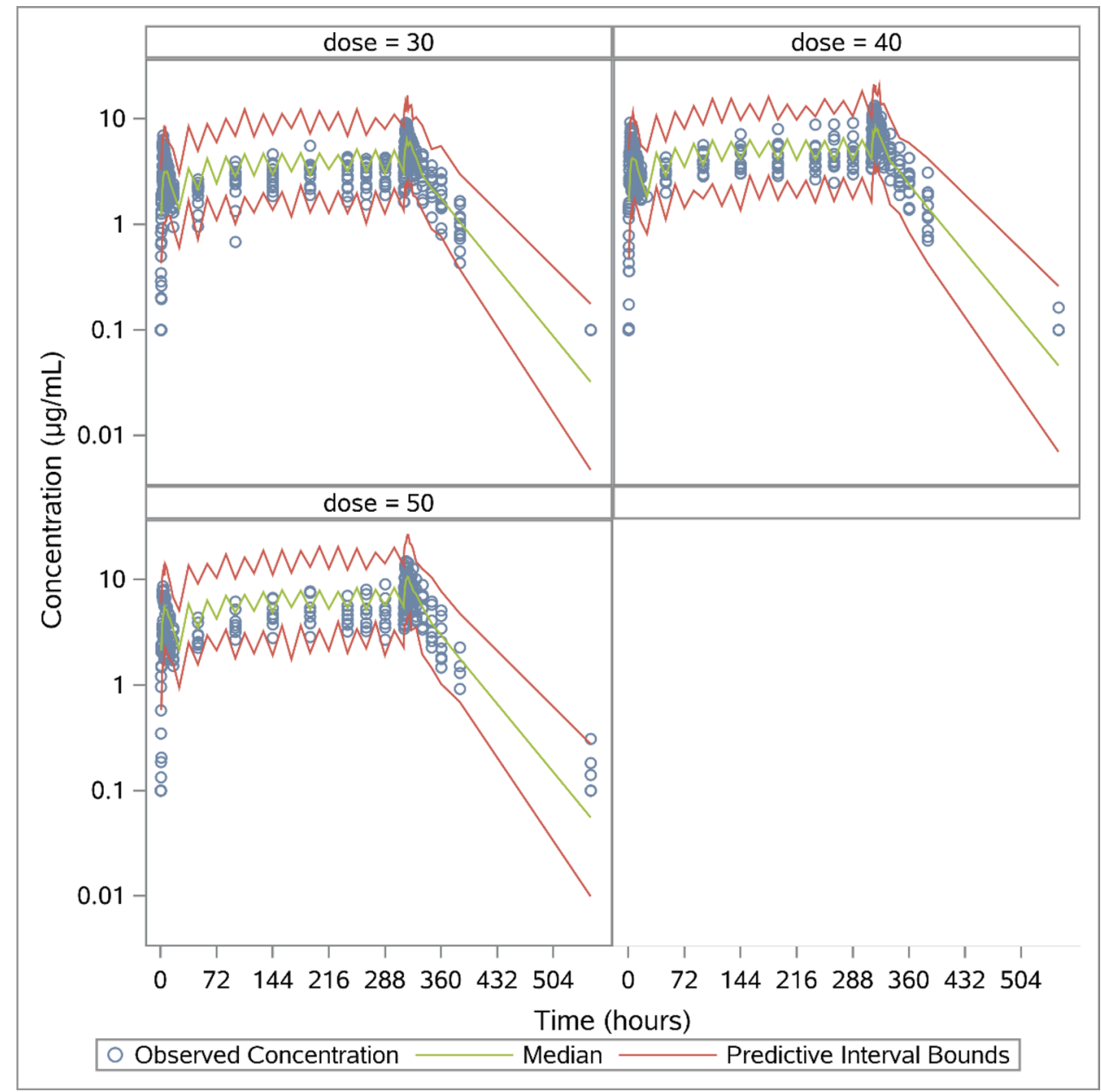

Acknowledgements The writing support and development of the population pharmacokinetic model by PharmaLex were funded by the study sponsor and collaborator, Immunic AG. We acknowledge Dr. Parveen Kumar (PhD Pharmacology), PharmaLex India Pvt. Ltd., New Delhi, India, for the writing support. We acknowledge Maud Hennion and Fabrice Nollevaux, PharmaLex Belgium S.A., Mont-Saint-Guibert, Belgium, for the support in the development of the population pharmacokinetic model.

Author contributions AM (clinical group) designed the clinical trial and oversaw data collection and data analysis; HK (preclinical development) designed and validated the analytical methods; MG (operations) and DV (science group) analyzed the data. All authors shared responsibility for the assessment and interpretation of data as well as reviewed and approved the final version of the manuscript before submission.

\section{Compliance with Ethical Standards}

Funding The writing support and development of the population pharmacokinetic model by PharmaLex were funded by the study sponsor and collaborator, Immunic AG. The authors declare that no other funding has been received for the conduct of this study.

Conflict of interest All authors are employees of Immunic AG and own stock of the parent company of Immunic AG.

Ethical approval The protocols for SAD and MAD studies were approved by the Institutional Ethics Committee (IECs). The study was conducted in accordance with the International Conference on Harmonization Guideline for Good Clinical Practice and Declaration of Helsinki and was approved in advance by the Institutional Ethics 
Committee. All subjects provided written informed consents before their participation.

Open Access This article is licensed under a Creative Commons Attribution-NonCommercial 4.0 International License, which permits any non-commercial use, sharing, adaptation, distribution and reproduction in any medium or format, as long as you give appropriate credit to the original author(s) and the source, provide a link to the Creative Commons licence, and indicate if changes were made. The images or other third party material in this article are included in the article's Creative Commons licence, unless indicated otherwise in a credit line to the material. If material is not included in the article's Creative Commons licence and your intended use is not permitted by statutory regulation or exceeds the permitted use, you will need to obtain permission directly from the copyright holder. To view a copy of this licence, visit http://creativecommons.org/licenses/by-nc/4.0/.

\section{References}

1. Kulkarni OP, Sayyed SG, Kantner C, Ryu M, Schnurr M, Sárdy $\mathrm{M}$, et al. 4SC-101, a novel small molecule dihydroorotate dehydrogenase inhibitor, suppresses systemic lupus erythematosus in MRL-(Fas)lpr mice. Am J Pathol. 2010;176(6):2840-7.

2. Fitzpatrick LR, Deml L, Hofmann C, Small JS, Groeppel M, Hamm S, et al. 4SC-101, a novel immunosuppressive drug, inhibits IL-17 and attenuates colitis in two murine models of inflammatory bowel disease. Inflamm Bowel Dis. 2010;16(10):1763-77.

3. Fitzpatrick LR, Small JS, Doblhofer R, Ammendola A. Vidofludimus inhibits colonic interleukin-17 and improves hapten-induced colitis in rats by a unique dual mode of action. J Pharmacol Exp Ther. 2012;342(3):850-60.

4. Herrlinger KR, Diculescu M, Fellermann K, Hartmann H, Howaldt S, Nikolov R, et al. Efficacy, safety and tolerability of vidofludimus in patients with inflammatory bowel disease: the ENTRANCE study. J Crohns Colitis. 2013;7(8):636-43.
5. Cao L, Weetall M, Trotta C, Cintron K, Ma J, Kim MJ, et al. Targeting of hematologic malignancies with PTC299, a novel potent inhibitor of dihydroorotate dehydrogenase with favorable pharmaceutical properties. Mol Cancer Ther. 2019;18:3-16.

6. Tan JL, Fogley RD, Flynn RA, Ablain J, Yang S, Saint-André $\mathrm{V}$, et al. Stress from nucleotide depletion activates the transcriptional tegulator HEXIM1 to suppress melanoma. Mol Cell. 2016;62(1):34-46.

7. Vaughn BP, Moss AC. Novel treatment options for ulcerative colitis. Clin Investig (Lond). 2013;3(11):1057-69.

8. Klotz L, Eschborn M, Lindner M, Liebmann M, Herold M, Janoschka C, et al. Teriflunomide treatment for multiple sclerosis modulates $\mathrm{T}$ cell mitochondrial respiration with affinity-dependent effects. Sci Transl Med. 2019;11(490):eaao5563.

9. Kohlhof H, Groeppel M, Muehler A, Vitt D. The DHODH inhibitor IMU-838/Vidofludimus calcium shows a superior compound profile as compared to the approved DHODH inhibitor Teriflunomide/Aubagio. ECTRIMS Online Library. Muehler A. 09/11/19; 278995; P635. https://onlinelibrary.ectrims-congress.eu/ectri ms/2019/stockholm/278995/andreas.muehler.the.dhodh.inhibitor. imu-838.vidofludimus.calcium.shows.a.html.

10. Rusai K, Schmaderer C, Baumann M, Chmielewski S, Prókai A, Kis E, et al. Immunosuppression with 4SC-101, a novel inhibitor of dihydroorotate dehydrogenase, in a rat model of renal transplantation. Transplantation. 2012;93(11):1101-7.

11. Sierakowski S, Dietrich B, Hentsch B, Ammendola A. Efficacy, safety and pharmacokinetics of vidofludimus, a novel oral immunomodulator, in patients with active rheumatoid arthritis on methotrexate background therapy: the Component Study. In: ACR/ARHP scientific meeting 11, Chicago, 2011.

12. Muehler A, Kohlhof H, Groeppel M, Vitt D. The selective oral immunomodulator vidofludimus in patients with active rheumatoid arthritis: safety results from the COMPONENT study. Drugs RD. 2019;19(4):351-66. 